\title{
Reaching beyond the Classroom through the use of Push Notifications
}

\author{
Michael Kallookaran \\ University of Braunschweig \\ m.kallookaran@tu-bs.de
}

\author{
Susanne Robra-Bissantz \\ University of Braunschweig \\ s.robra-bissantz@tu-bs.de
}

\begin{abstract}
New technologies enable educators to modify their teaching methods and extend their reach beyond the classroom. One of these methods that can be applied to communicate with students is through the use of push notifications on smartphones. Instead of relying on students to use a spaced learning approach, which is proven to be more efficient than trying to study something in a short period of time, it is now possible to remind them to learn and stick to a learning schedule from day one. For this research we implemented a mobile application that enables students to subscribe to a course and get push notifications on their smartphone if new questions are being made available by the teacher. The experiment we conducted shows that students who use push notifications are returning more often to the application and better stick to a given learning schedule than students who don't have push enabled.
\end{abstract}

\section{Introduction}

The past few years have seen a remarkable growth in smartphone sales [1] and mobile device usage [2]. Especially students, which we will focus on in this paper, have a noteworthy device ownership [3]. It is therefore not surprising that educational apps are entering the market [4] that are able to enhance learning effectiveness and a course in general [5]. Highly frequented courses where the amount of participants is exceedingly high are furthermore leading to a drop of interactivity between teacher and students, and among students [6]. This is where mobile apps can help the educators as well as the students to better stay in touch, interact with each other and get better feedback.

This paper will focus on interaction learning, which is one part to consider when establishing a mobile learning application [7]. It will show, how an artifact, which is a part of our overall educational mobile app, will enable students to better follow the instructions of a teacher through the use of push notifications when not in class. Students will receive multiple choice question for learning the meaning of certain vocabulary. The entire developed application that includes this artifact is called C4mpUs, however, we will reference the developed artifact with the same name from this point on. C4mpUs has been built from the ground up to further integrate gamification as a mean to increase the motivation to use it. Gamification has been successfully used and tested in several different fields [8] such as tourism [9], health [10], or education [11]. This paper will briefly discuss the design and the development of C4mpUs and how design science helped to create it. The objective is to get students to stick to a schedule a teacher has laid out and ultimately use the spaced learning approach when it comes to review their learning material. We are trying to get students to learn more frequently instead of having them try to mass their entire learning material into a couple of days before an exam. It is our aspiration that students will change their learning habit by adapting the successfully proven spaced learning approach [12], [13] which will then hopefully have a positive effect on their overall academic performance. The use of gamification will motivate participants to use our artifact, and push notification will constantly try to influence their behavior to stick to a given schedule.

\section{Teaching with technology}

Integrating technology in schools has been an important research interest for the past couple of decades [14]. A focus point has been how new technologies have been introduced into education and how they allow for new types of learning experiences [15]. It is, however, not enough to introduce a new technology to a classroom setting because "it is not the technology which changes things; it is the way in which people use the technology that has the potential to change our classroom practice" [16, p. 5]. A challenging difficulty will be to overcome the mindset of the teachers and change their behavior towards new possibilities. It is necessary to address their views about learning, teaching, and technology [17]-[19]. An important question that needs to be addressed now, in this context, is what a teacher needs to know in order to appropriately incorporate and use technology in their classroom [20]. Giving teachers the opportunity to 
seamlessly connect and interact with students even though there is no class in session will require more research that showcases the opportunities and the risks connected to these new possibilities. In this context Koole [7] proposed the Framework for the Rational Analysis of Mobile Education (FRAME), a model for framing mobile Learning, that is an important framework which was developed over the past few years in order to address these issues.

\subsection{Frame}

Mobile Learning is defined by the FRAME model as the composition of social interaction, human learning capacities and mobile technologies. It addresses the fact how mobile technologies can be beneficial to students and that it is necessary for educators to also make their learning material not only available through classic channels but also for mobile access. Furthermore, the FRAME model tries to give advice on what needs to be addressed in formal and informal settings in order to still achieve an effective mobile learning environment. This environment further considers the fact of students being location independent, meaning that they are able to freely move in their regular environments, as well as virtual ones, and still be able to collaborate with others at any given time [7]. The FRAME model consists of different parts which are depicted in Figure 1.

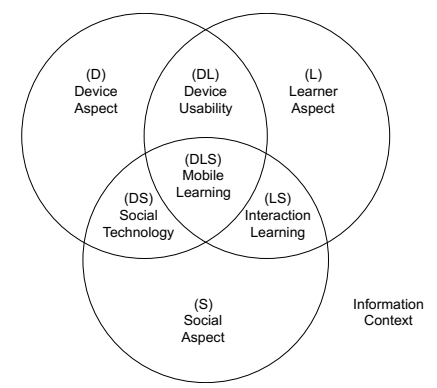

Figure 1: Frame Model [7]

The intersection we will focus on in this paper is the device usability intersection which combines mobile device qualities with cognitive tasks. The intersection addresses aspects of portability, psychological comfort, satisfaction as well as information availability. Portability refers to the physical dimensions of the device and how easy it is for a user to move around with the device. How intuitive and easy-to-use a device is, is being covered by the psychological comfort aspect. Nielsen in fact emphasizes that "the system should be easy to learn so that the user can rapidly start getting work done with the system" [21, p.26]. In contrast satisfaction is concerned with the looks of the interface and the device, as well as its functionality. The last criteria, namely information availability is an important key concept for mobile learning. It is for example concerned with the aspect of when and where a user is able to retrieve stored information [7]. In regard to the mentioned criteria, it is necessary to use an intuitive, easy-to-use mobile device in order to let the user focus on his or her task, rather than on how to handle or use a device.

Our main focus point in this paper will be to address information availability. We will give the students the opportunity to subscribe to newly made available learning questions through push notifications and determine if this approach is favorable compared to relying on a student's self-determined schedule for learning.

\section{Background}

It can be hard to motivate students to learn course relevant material, especially, as it is in our case, when only asking for the retention of vocabulary. The differences between retaining information and actually applying and using them is very different. Which level to target is part of an educator's choice on how and what to teach.

\subsection{Bloom's pyramid}

In 1956 Bloom et. al classified six different educational objectives in their taxonomy which were later revised by Krathwohl. This revised taxonomy is often used to determine what students should learn as a result of instructions. The lower-order thinking skills are here defined as the things that students are able to retain and recall from memory. After that comes the understanding of information, then applying it, analyzing it, evaluation and then finally on the top are the higher-order thinking skills that enable students to create something new out of the acquired knowledge [22], [23].

Our focus point for this paper will be to solely target the lower-end of Bloom's revised taxonomy. By trying to get the students to remember certain vocabulary it is clear that we are only trying to get them to recall information from memory. In further studies it will be advisable to also target higher-order thinking skills. However, especially because we are only targeting the lower-end of Bloom's pyramid it is necessary to further motivate the students to use C4mpUs. For this purpose, we chose to integrate gamification.

\subsection{Gamification}


A very common definition for gamification was made by Deterding et. al who called it "the use of elements of game design in non-game contexts" [24, p.2]. Gamification has become more and more popular in recent years [25] and is often used to influence a person's behavior, especially his/her motivation [26], [27]. It also offers the ability to make an application more engaging and interesting [28]. This makes it an adequate instrument for trying to persuade students to use $\mathrm{C} 4 \mathrm{mpUs}$ for learning vocabulary. It is, however, important to keep in mind that it is necessary to satisfy several requirements when making use of gamification. These requirements, such as to know what needs to be accomplished, to know the interests and goals of the targeted students, choose game elements that are adequate for the situation, as well as investigate the effectiveness of the result, will prevent learning objectives to be weakened rather than being enhanced when gamifying the learning experience [29]. Learning objectives need to be identified and defined before it is possible to add game elements and game mechanics to non-game contexts. Not considering the effects of gamification and just applying it to learning activities has already led to criticism calling it not only "pointsification" [30] but also exploitive [31]. An example for gamification is the mobile application developed by Nissan called Carwings that tries to get the driver of an electric car to drive more ecologically and therefore conserve battery power for the ability to drive a longer distance [32].

It is our goal to use gamification in order to motivate our students to consistently use our developed artifact for a learning purpose even though there is no class in session.

\subsection{Spaced learning}

A fundamental issue that a learner is confronted with outside of the classroom is when to learn. Even though an instructor is able to suggest a time and the frequency to learn, it is up to the student to follow these instructions when they are unsupervised. However, it should be clear to the student that it is not indifferent when or how to learn. As early as 1885 Ebbinghaus determined that it is better to use a distributed approach with several short iterations for recalling memories, rather than trying to achieve the same result in just one long session [33]. This approach, to leave time between learning sessions, is called spacing and has proven to be more effective in comparison to a massed approach where no time is left in between learning sessions [12], [13]. This effect is especially useful in education where it can lead to better memory retention without having to invest more learning time [34].

Nonetheless, it has been shown that students think that massing is more effective than spacing [35] which makes it more important to teach students the benefits of using a spaced learning approach. However, the teacher is limited to his/her lecture hours in order to clarify the benefits and promote spaced learning. Further, it is challenging to implement this new approach in an efficient and practical manner [36]. Before and after classroom hours it is up to the students to actually adapt this behavior.

Our approach is to further extend the reach of a teacher to suggest an appropriate time to learn without being limited to classroom hours. For this purpose, the teacher is able to use C4mpus in order to send out push notifications with multiple choice questions to his/her students when he/she sees fit. This means that we will not only use gamification in order to have students find pleasure in using the application but we will also enable students to use push notification in order to be reminded to study. This way a student can be reminded to stick to a given schedule even if there is no class in session and if he/she is distracted for any given reason.

\subsection{Pushing versus pulling}

The key difference between push and pull is the time for receiving the data. When push is being used then the user is able to receive the data with almost no latency from the time it is being made available. For the user it can be perceived as an unscheduled delivery at any given time. Otherwise, if pull is being used then it is up to the user to check or request for new or updated data. Although, for achieving a similar result in comparison to push, so that a user still gets updated data with a low latency, it is necessary to have the pull mechanism automatically check for updates in a specific time interval [38]. This technique is also often referred to as "smart-pull" (e.g [39], [40]).

Due to its ability to send data at an unscheduled point in time and thus, significantly improving the response time for accessing the web, has made the push technology very popular among internet users. Hauswirth and Jazayeri show in Figure 2 how the push and pull mechanism differ from each-other.

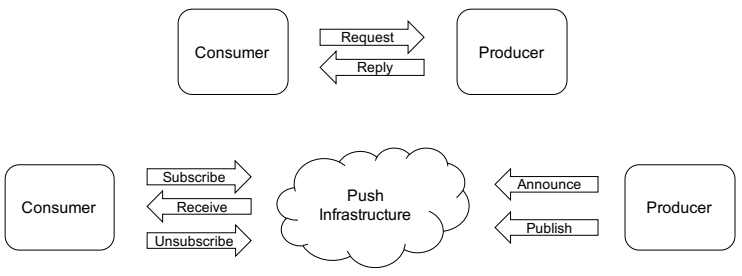

Figure 2: Push vs. pull [41] 
The top part shows how a consumer or client needs to make a request to a producer or a server in order to get a response. On the bottom part is the representation of the push mechanism. Hauswirth and Jazayeri show here the publish/subscribe mechanism. A user offers a push infrastructure the insight on what he/she is interested in and subscribes to a channel if interested. Users are basically specifying the information they want to receive. The producer on the other side is able to make announcements for different channels and then publish them to the push infrastructure. If the subscribed channel of the consumer matches an announcement published by the producer, then the announcement is pushed to the consumer. If the consumer is no longer interested in receiving pushed content from a specific channel then he/she can unsubscribe from it [41], [42]. In our study we will enable participants to subscribe to a course and either enable or disable push notifications.

\subsection{Push notification for smartphones}

Due to the advantages of push and pull, the literature suggests to use both protocols because of their dynamic nature [41], [43]. However, when considering to implement the push mechanism on a smartphone rather than on a computer, it is necessary to get familiarized with the respective infrastructures. The most commonly used smartphones or rather smartphone operating systems are Android and iOS. Android has the biggest market share in the world. However, the distribution and importance varies across different countries [45, p.210], or certain organizations and sectors [46, p.13]. This is why it is of preference to know the target market and then choose the platforms accordingly [47, p.34]. Push notification, however, are not only very convenient when it comes to be notified on time, they also allow for a lower battery consumption [48, p.88], which is considered an important feature when buying, [49] or for deleting a specific application, on a smartphone [50, p.9].

Through the usage of push notification in C4mpUs educators are now able to send out vocabulary as multiple choice questions almost instantly to their students. However, as already mentioned this feature can lead to the deletion of an application if overused, as well as leads to the question on when to send out the messages during the day.

\subsection{Diurnal efficiency}

As soon as 1916 Gates found out that there is a variation of diurnal efficiency when it comes to memory and association [51]. However, not only these factors are being affected in the course of the day but also the ability to concentrate. Klein found out that there is an age-related difference when looking at the ability to concentrate and at the time of the day [52]. This discovery is especially important when considering the fact that concentration has an effect on school performance [53]. Researchers have therefore argued that school schedules should be altered so that students are able to use their peak hours of concentration to learn and take tests [52], [54]. Individuals who are evening types for example, who go to bed late at night, who are obligated to stick to an early schedule might show sleep-deficiency [55]. This negative effect can the lead to a drop in academic performance [56].

However, in order to adapt to the different circadian types, it is necessary to first determine to which group each individual belongs to. For this purpose, many different methods have been developed such as the Munich ChronoType Questionnaire [57], the Composite Scale of Morningness [58] or the Morningness-Eveningness Questionnaire (MEQ) [59]. Due to its frequent usage and translation into different languages such as German [60] we chose to use the MEQ. The MEQ differentiates between five different types of individuals being a 1) definite morning type, 2) moderate morning type, 3) neither type, 4) moderate evening type, and lastly a 5) definite evening type [59].

\subsection{Understanding behavior}

It is, however, not only important to know a student's preference for learning but also be able to influence him/her if he/she might not use an ineffective learning strategy. However, influencing human behavior is very difficult because it is hard to understand in the first place. It is made out of a lot of different aspects which need to be considered and which can be all approached in a different way [61]. It has been argued for years what a good predictor for behavior could be. Aarts et. al [62] come to the conclusion that past behavior, that has been performed many times in the past, becomes habitual and is therefore a good predictor for future behavior.

How complex human behavior can be best showcased by the example of smoking. Despite the fact that individuals are aware of the fact that smoking can endanger his/her health they are still not willing to quit. This leads to hard to predict behavior since they are not necessarily following rational or logical thinking [63].

The SNAP model tries to explain human behavior and how it can change over time. It considers the fact that an individual might return or move to another behavior at any given time, "depending on the momentary balance of wants and needs" [63, p.280]. In contrast to the Stages of Change Model, which is 
another popular model, this model does not rely on a linear approach but rather assumes uncertainty when it comes to behavior. This way it is possible for a person who stopped smoking for example to move back to smoking at any given point in time [63].

If we compare this to learning, it is our aim to get the students to adapt a new behavior, that is to use spaced learning. Classes offer educators the possibility to move them from not using it to adapting it. However, since it is possible for them to move back to their old learning strategy at any given time, it is important to remind them to keep using it as well as set incentives to go back to spaced learning if necessary. Especially for spaced learning where there are time frames in between learning periods, which can be minutes or hours but also weeks and even months long, it is important to stick to the schedule. By implementing push notifications in a learning application, we are enabling educators to set incentives even if no class is in session.

\subsection{Persuasive technology}

Human behavior can be not only very hard to comprehend but also very difficult to influence. However, there have been many attempts to do so. One of these attempts is through the use of persuasive technology [64]-[66]. An example of this persuasive technology in combination with gamification is the previously mentioned Carwings mobile application by Nissan. It allows users to compare each-others performance in a ranking. The goal is to drive more ecologically and save battery power in order to be able to drive for a longer distance [32]. However, it is not only possible for technology to influence the behavior of a person but also for design in general [67].

In order to create a persuasive technology that persuades individuals to adapt another behavior, Fogg [68] created an eight-step design process which included things such as targeting only one behavior, finding a receptive audience, choosing the right channel as well as look for comparable successful strategies that targeted a similar behavior, audience and technology channel. Once they have been identified it is possible to imitate them and test them repeatedly. The last step is to test the newly created technology in a different environment such as targeting an audience that is less receptive [68].

Our goal for this study was to get participants to use the application at the specified times. The targeted behavior was to get the students to interact more frequently with the developed mobile application through the use of push notifications. Since we are letting students install the application on their own smartphone we can be sure that they are already familiar with this technology.

\section{Research approach}

In order to create our artifact called C4mpUs that tries to get students to learn more efficiently, while not being in class, and to scientifically evaluate its benefits, we chose to use the Design Science Research (DSR) approach. DSR "creates and evaluates IT artifacts intended to solve identified organizational problems" [69, p.77].

\subsection{Design science research approach}

The article of Hevner et al. in 2004 tried to "describe the performance of design-science research in Information Systems (IS) via a concise conceptual framework and clear guidelines for understanding, executing, and evaluating the research" [69, p.75]. This led to the wide spread adoption of DSR as a legitimate research approach in Information Systems. Later Gregor and Hevner tried to further specify what DSR is and said that it "involves the construction of a wide range of socio-technical artifacts such as decision support systems, modeling tools, governance strategies, methods for IS evaluation, and IS change interventions" [70, p.337]. However, this was not the first research in this field. In 1990 Nunamaker et al. [71] already proposed a multimethodological approach to IS research that would integrate a system development in the research process which would consist of the theory building, systems development, experimentation and observation.

Working with the previously determined results Peffers et al. created another popular DSR method which used a six step approach. These steps consist of 1) problem identification and motivation, 2) define the objectives for a solution, 3) design and development, 4) demonstration, 5) evaluation, and lastly 6) communication. They also offered multiple possible research entry points why research would be initiated. These points included the initiation of research because of a problem that needs to be addressed, an objective that needs to be reached, designing and developing an artifact, and because of a possible client or context reason [72]. Our approach is to get students to learn more efficiently, while not being in class and stick to the laid out spaced learning approach. This should lead to less of an effort for a student to learn, as well as enhance the retention level of the learned information. This can be defined as a problem-centered approach according to Peffers et al. [72] after which we then defined our objectives and later created our artifact called C4mpUs. 


\subsection{Approach}

Figure 3 visualizes the concept of spaced learning and how a typical experiment is constructed. For our experiment we asked for volunteers who would participate in an experiment that teaches English to foreigners, in exchange for course credit. We followed the approach of spaced learning and provided participants with 40 flashcards containing an English word with its German counterpart and asked them to learn them. This would represent the first step of a spacing experiment to Study Something Once. After a period of time we then asked them to put the flashcards away and answer a test, asking for the meaning of the words in a multiple choice manner, with four German words as a possible choice. This way we were able to see how well they retained the words after the initial study session.

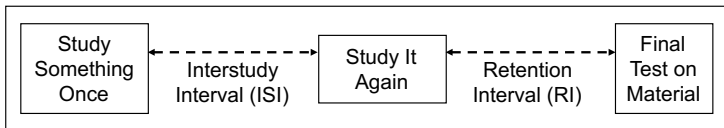

Figure 3: Design of a spacing experiment [73]

We then introduced our developed artifact C4mpUs to them and showed them how it works. The artifact enables students to subscribe to a course which contains multiple choice questions. Participants can use the application to answer these questions and receive points for their first given answer. These points will then be displayed in an anonymized ranking. This means participants are able to answer a question multiple times but are only rewarded points for their first try. A course was created for this experiment containing 20 out of the 40 English words, which were previously introduced to them on flashcards. We chose to make only half of the words available to them in order to validate the effectiveness of $\mathrm{C} 4 \mathrm{mpUs}$ and to ensure no manipulation.

All provided questions in $\mathrm{C} 4 \mathrm{mpUs}$ were put into a multiple choice question format with one English word and four possible German words to choose from (E120). Only one of these choices represented the right solution. The English words were taken from a list of the standardized GRE Test. This setting best represents the learning situation of a student who has the learning material at his/her disposal right after class. Furthermore, in order to avoid that participants would just remember the position of a right response, within a multiple choice question, we chose to randomize the order of the given possibilities, each time a question would be opened. This means, for example, that the right solution for a question would sometimes be position two and then the next time maybe position four. In order to promote spaced learning, we informed all the participants that four additional multiple choice questions would be made available to them each day over the next ten days. We would leave one spare day right before the final test where no further questions would be made available to them. Figure 4 showcases our approach. At the bottom you can see the questions they had available since the beginning (E1-20). The middle part represents the second step in a spacing experiment to Study It Again. Here you can see that we delivered additional questions in a different format for the period of ten days and that we reiterated those questions twice. This different format consisted of flipping languages but still asking for the same words previously introduced. This means that we kept the English word with its German counterpart but left the user to choose from the right English word from four possible choices rather than the right German word (GE1-20). By doing this we offered participants the possibility to reiterate through the given words and challenge them to point out the right answer in both conditions.

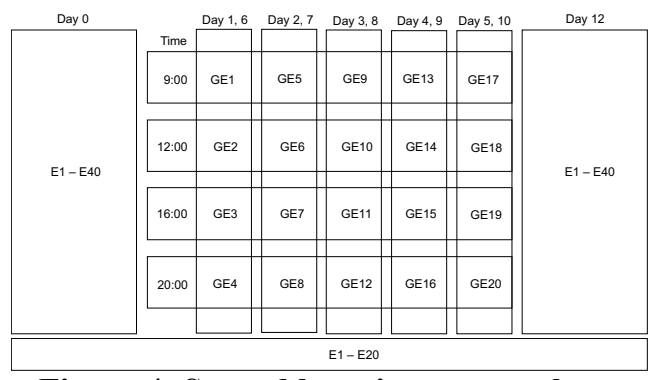

Figure 4: Spaced learning approach

The timing of the delivery was chosen according to the MEQ that asks participants for their hours of peak performance. This question gives the participants four time frames to choose from, which stand for several hours during the day. We chose the mean time of the respective time frames so that a morning person for example gets at least one question at their desired time. Finally, the left side of Figure 4 shows the test they had to take at the beginning of the study whereas the right part shows the last step in a spacing experiment the Final Test on Material (E1-40). Participants were further randomized and assigned to two different groups. One group would have push notifications enabled and receive the questions right on their device at the respective time. The control group would need to pull the information after it was made available to them. Both groups were made aware of the fact when and how often questions would be added to C4mpUs. Participants were instructed to learn the vocabulary over the next two weeks. We encouraged the benefit of the schedule but left it up to them to stick to it. 


\section{Evaluation}

The study was conducted with 41 participants that received course credit as part of their degree program as a student. All of them were randomly assigned a group, either receiving push notifications or not. However, one participant dropped out during the study and one participant broke his/her phone and could not continue, leaving us with a total of 39 participants. Four other participants chose to never enable push notification, even though they were instructed to do so. Since they never did enable push notifications we reassigned them afterwards to the group of not having received push notifications. The distribution of the participants can be found in Table 1 .

\begin{tabular}{|l|l|l|l|}
\hline & Push & No-Push & Total \\
\hline Male & 8 & 14 & 22 \\
\hline Female & 6 & 11 & 17 \\
\hline Total & 14 & 25 & \\
\hline
\end{tabular}

Table 1: Participant distribution

In order to determine the effect of having or not having push notification enabled we recorded, with the consent of the participants, data usage of C4mpUs. These included the amount of times each participant chose to open $\mathrm{C} 4 \mathrm{mpUs}$, time spent in $\mathrm{C} 4 \mathrm{mpUs}$, how many times he/she chose to answer a question, as well as how many times he/she looked at the ranking.

When comparing the ten days where new questions were made available we can say that the amount of opening the app was significantly higher in the push group (mean=32.21) than in the control group (mean $=12.96, \mathrm{t}=2.9829, \mathrm{p}=0.008402, \mathrm{df}=16.881$ ). This means that we were able to get participants to return to the app more often when we send out push notifications. We further identified the circadian types of the participants by evaluating their MorningnessEveningness Questionnaire (MEQ) that they filled out at the beginning of the study. We then looked at the time when participants chose to answer questions and evaluated the mean time of activity. Table 2 showcases our findings.

\begin{tabular}{|l|l|l|l|l|}
\hline & Push & & No-Push & \\
\hline Circadian Type & Amount & $\begin{array}{l}\text { Mean } \\
\text { Time }\end{array}$ & Amount & $\begin{array}{l}\text { Mean } \\
\text { Time }\end{array}$ \\
\hline Def. Morning & 1 & $15: 43: 52$ & 2 & $16: 15: 08$ \\
\hline Mod. Morning & 5 & $14: 45: 21$ & 8 & $16: 54: 34$ \\
\hline Intermediate & 8 & $15: 27: 38$ & 11 & $16: 28: 14$ \\
\hline Mod. Evening & 0 & & 3 & $14: 12: 26$ \\
\hline Def. Evening & 0 & & 1 & $05: 32: 37$ \\
\hline
\end{tabular}

Table 2: Mean time to answer
We also looked at the reaction time of participants when answering a new question. The group with push notifications took on average 37 hours and 53 seconds to answer a question (SD: 2.05hours) whereas the group without the push notifications took 44 hours 23 minutes and 35 seconds (SD: 1.75 hours). It has to be mentioned that not all of the participants actually provided an answer to all of the questions. However, in every case at least 8 answers were given. In the case of missing values, we calculated the mean response time for a student with the amount available to us.

As a last step we compared the mean time spend in the app while using it. We can say that the mean time of seconds spent in the application was significantly lower for the push group (mean=49.19) than in the control group (mean=90.98, $\mathrm{t}=-3.395, \mathrm{p}=0.009341$, $\mathrm{df}=37$ ). This means users who received push notifications did use the application for a shorter amount of time.

\subsection{Discussion}

The gathered data shows that push notifications have an effect on the usage of an application. Users who enabled push notifications returned more often to $\mathrm{C} 4 \mathrm{mpUs}$ than the control group, who didn't enable it. Being able to get users to come back to the application might be helpful when trying to solicit spaced learning. Since spaced learning can be applied with various time frames, leaving different amounts of time in between the respective learning sessions, it can be very helpful to get the users attention, especially after a long spaced time frame. Being able to remind him/her of the next learning session might be crucial to keep the student on schedule. Furthermore, the time it took a participant to answer a newly made available question did differ by several hours. Questions were answered by the push group on average approximately seven hours faster than the control group.

Even though the push notification group did enter the application more often than the control group, they did spend significantly less time in $\mathrm{C} 4 \mathrm{mpUs}$. This might be explained by the fact that when interacting with a push notification the application takes a user directly to the question. Users without a push notification, just entering the application on their own, will need to navigate and find the right question themselves. Furthermore, the push notification gives the user a preview of the question on the lock screen or notification center. This gives the user a time advantage in answering it, thus, also reducing the need to stay inside the application. The mean time of answering a question for each circadian type of participant did also show us that time differences within these types might not be too important. As 
Table 2 shows the circadian type of the individuals did not have a big effect on the response time. Definite morning types for example answered on average in the afternoon rather than in the morning. This makes us believe that we might neglect the circadian type of an individual as long as information, and time of interaction are kept short. However, due to the small sample size more research is needed to better understand these dependencies.

Even with C4mpUs addressing information availability when it comes to mobile learning (refer to Figure 1) it still needs to address the best time for each individual to receive new information. If applications, such as C4mpUs, will allow teachers to interact with students at any given time, then these applications should also consider the best time for delivery, depending on other variables such as the owner's circadian type or context. From a pedagogical point of view, it should further be possible to address other areas of Bloom's revised taxonomy. Furthermore, it has to be said that the sample size of both groups was very small and that participants may not have taken the study as serious as a regular class. Even though participants received course credit for the study they were not required to achieve a specific score in the study in order to pass it. This might have affected the motivation of the participants to behave in a normal learning manner.

\section{Conclusion}

We created and evaluated an artifact called C4mpUs that uses push notification to alert participants of newly made available multiple choice questions. Gamification was further used to motivate participants to use the artifact throughout our experiment. Since human behavior is difficult to predict, push notification can be an important tool to set incentives to adopt or stick to a new behavior that is being promoted by a teacher. To evaluate its effectiveness, we gave two groups the same schedule for learning new multiple choice questions. One group had push notifications enabled and directly received the question when made available. The other group was not reminded by this mechanism and solely relied on their personal schedule.

The group with push notifications returned more often to C4mpUs but on average spend less time in the application. This might be due to the fact that the notification enables the user to directly go the question and preview it before even entering the application. More research is needed to see how much circadian types can be influenced by this new educational method of delivering information to smartphones at any given time.
The results of the artifact presented in this study show the difference on being able to send direct messages to enrolled participants. However, more research is needed to determine the best time for delivering information as well as to determine if it wouldn't be the best case to deliver information asynchronously depending on a circadian type. This means that an educator would be able to make information available at a given time but that the application would determine the best time of delivery on a case to case basis.

\section{References}

[1] eMarketer. (2014, December) 2 billion consumers worldwide to get smart(phones) by 2016 [Online]. Available: http://www.emarketer.com/Article/2-Billion-ConsumersWorldwide-Smartphones-by-2016/1011694

[2] comScore. (2015, March) A digital update, by the numbers. [Online]; Available: http://www.statista.com/ statistics/294438/us-digital-plaform-usage-duration/

[3] Pearson. (2013, April) Pearson student mobile device survey 2013. [Online]. Available: http://www.pearsoned.com/wp-content/uploads/PearsonStudent-Mobile-Device-Survey-2013-National-Report-onCollege-Students-public- release.pdf

[4] C. Shuler, Z. Levine, and J. Ree, "ilearn ii - an analysis of the education category of apple's app store," The Joan Ganz Cooney center, Tech. Rep., January 2012.

[5] M. Riconscente, "Mobile learning game improves 5th graders' fractions knowledge and attitudes," Los Angeles: GameDesk Institute, 2011.

[6] C. Hansen and C. Jensen, "Evaluating lecture comprehension," Academic listening: Research perspectives, pp. 241268, 1994.

[7] M. L. Koole, "A model for framing mobile learning," Mobile learning: Transforming the delivery of education and training, vol. 1, no. 2, pp. 25-47, 2009.

[8] J. Hamari, J. Koivisto, and H. Sarsa, "Does gamification work?-a literature review of empirical studies on gamification," in System Sciences (HICSS), 2014 47th Hawaii International Conference on. IEEE, 2014, pp. 3025-3034.

[9] F. Xu, J. Weber, and D. Buhalis, "Gamification in tourism," in Information and Communication Technologies in Tourism 2014. Springer, 2013, pp. 525-537.

[10] D. King, F. Greaves, C. Exeter, and A. Darzi, "'gamification': Influencing health behaviours with games," Journal of the Royal Society of Medicine, vol. 106, no. 3, pp. 76-78, 2013.

[11] J. J. Lee and J. Hammer, "Gamification in education: What, how, why bother?" Academic Exchange Quarterly, vol. 15, no. 2, p. 146, 2011.

[12] S. K. Carpenter, N. J. Cepeda, D. Rohrer, S. H. Kang, and H. Pashler, "Using spacing to enhance diverse forms of learning: Review of recent research and implications for instruction," Educational Psychology Review, vol. 24, no. 3, pp. 369-378, 2012.

[13] N. J. Cepeda, H. Pashler, E. Vul, J. T. Wixted, and D. Rohrer, "Distributed practice in verbal recall tasks: A review 
and quantitative synthesis." Psychological bulletin, vol. 132, no. 3 , p. $354,2006$.

[14] D. L. Lowther, F. A. Inan, J. Daniel Strahl, and S. M. Ross, "Does technology integration "work" when key barriers are removed?" Educational Media International, vol. 45, no. 3, pp. 195-213, 2008.

[15] C. Dede, "The evolution of distance education: Emerging technologies and distributed learning," American Journal of Distance Education, vol. 10, no. 2, pp. 4-36, 1996.

[16] A. A. Carr, D. H. Jonassen, R. M. Marra, and M. E. Litzinger, "Good ideas to foment educational revolution: The role of systemic change in advancing situated learning, constructivism, and feminist pedagogy." Educational Technology, vol. 38, no. 1, pp. 5-15, 1998.

[17] J. H. Sandholtz, C. Ringstaff, and D. C. Dwyer, Teaching with technology: creating student-centered classrooms. New York: Teachers College Press, 1997.

[18] N. Bitner and J. Bitner, "Integrating technology into the classroom: Eight keys to success," Journal of technology and teacher education, vol. 10, no. 1, pp. 95-100, 2002.

[19] Y. Zhao and G. A. Cziko, "Teacher adoption of technology: A perceptual control theory perspective," Journal of technology and teacher education, vol. 9, no. 1, pp. 5-30, 2001.

[20] Y. Zhao, What should teachers know about technology?: Perspectives and Practices. IAP, 2003, vol. 2.

[21] J. Nielsen, Usability Engineering, ser. Interactive technologies. AP Professional, 1994. [Online]. Available: https://books.google.de/books?id=95As2OF67f0C

[22] B. S. Bloom, M. Englehart, E. Furst, W. Hill, and O. Krathwohl, "Taxonomy of educational objectives: The classification of educational goals. handbook i: Cognitive domain. white plains, ny," 1956.

[23] D. R. Krathwohl, "A revision of bloom's taxonomy: An overview," Theory into practice, vol. 41, no. 4, pp. 212-218, 2002.

[24] S. Deterding, R. Khaled, L. E. Nacke, and D. Dixon, "Gamification: Toward a definition," in CHI 2011 Gamification Workshop Proceedings, 2011, pp. 12-15.

[25] S. Deterding, M. Sicart, L. Nacke, K. O'Hara, and D. Dixon, "Gamification. using game-design elements in nongaming contexts," in CHI'11 Extended Abstracts on Human Factors in Computing Systems. ACM, 2011, pp. 2425-2428.

[26] K. M. Kapp, The gamification of learning and instruction: game-based methods and strategies for training and education. John Wiley \& Sons, 2012.

[27] K. Werbach and D. Hunter, For the win: How game thinking can revolutionize your business. 2012. Wharton Digital Press,

[28] G. Zichermann and C. Cunningham, Gamification by design: Implementing game mechanics in web and mobile apps. " O’Reilly Media, Inc.”, 2011.

[29] A. F. Aparicio, F. L. G. Vela, J. L. G. Sanchez, and J. L. I. Montes, "Analysis and application of gamification," in Proceedings of the 13th International Conference on Interaccion Persona-Ordenador. ACM, 2012, p. 17.

[30] M. Robertson, "Can't play, won't play," Hide \& Seek, vol. 6, p. 2010, 2010.
[31] I.Bogost, "Why gamification is bullshit," The Gameful World: Approaches, Issues, Applications, pp. 65-80, 2015.

[32] I. Blohm and J. M. Leimeister, "Design of it-based enhancing services for motivational support and behavioral change," Business \& Information Systems Engineering, vol. 5, no. 275-278, 2013.

[33] H. Ebbinghaus, Ueber das Gedächtnis, Untersuchungen zur experimentellen Psychologie von Herm. Ebbinghaus. Duncker \& Humblot, 1885.

[34] D. Rohrer and H. Pashler, "Increasing retention without increasing study time," Current Directions in Psychological Science, vol. 16, no. 4, pp. 183-186, 2007.

[35] N. Kornell, "Optimising learning using flashcards: Spacing is more effective than cramming," Applied Cognitive Psychology, vol. 23, no. 9, pp. 1297-1317, 2009.

[36] I. V. Kapler, T. Weston, and M. Wiseheart, "Spacing in a simulated undergraduate classroom: Long-term benefits for factual and higher-level learning," Learning and Instruction, vol. 36, pp. 38-45, 2015.

[37] M. Franklin and S. Zdonik, ““data in your face”: push technology in perspective," in ACM SIGMOD Record, vol. 27, no. 2. ACM, 1998, pp. 516-519.

[38] J. T.-S. Quah and G. L. Lim, "Push selling — multicast messages to wireless devices based on the publish/subscribe model," Electronic Commerce Research and Applications, vol. 1, no. 3, pp. 235-246, 2003.

[39] T. Käpylä, I. Niemi, and A. Lehtola, "Towards an accessible web by applying push technology," in Proc. Fourth ERCIM Workshop, User Interfaces for All, 1998, pp. $19-21$.

[40] K. M. Dubas and C. Sylla, "Webcasting/push technology in intranets and extranets," Proceedings... Orlando: POMS, 2001.

[41] M. Hauswirth and M. Jazayeri, "A component and communication model for push systems," in Software Engineering-ESEC/FSE'99. Springer, 1999, pp. 20-38.

[42] M. Hauswirth, "Internet-scale push systems for information distribution-architecture, components, and communication," 1999.

[43] P. Deolasee, A. Katkar, A. Panchbudhe, K. Ramamritham, and P. Shenoy, "Adaptive push-pull: disseminating dynamic web data," in Proceedings of the 10th international conference on World Wide Web. ACM, 2001, pp. 265-274.

[44] (2015, August) Idc: Smartphone os market share. [Online]. Available: http://www.idc.com/prodserv/smartphoneos-market-share.jsp

[45] Ofcom, "International communications market report," Tech. Rep., December 2013.

[46] G. Technology, "Mobility index report q2 2015," Tech. Rep., August 2015.

[47] J. T. Plummer, "The concept and application of life style segmentation," the Journal of Marketing, pp. 33-37, 1974.

[48] P. C. Dinh and S. Boonkrong, "The comparison of impacts to android phone battery between polling data and pushing data," in IISRO Multi-Conferences Proceeding. Thailand, 2013, pp. 84-89.

[49] uSwitch, "3d screens?! smartphone makers should focus on the basics to win us over, say 12.5 million british tech fans." 
[50] M. Brown, "The new mobile mantra," Tech. Rep., October 2015.

[51] A. I. Gates, Diurnal variations in memory and association. University of California Libraries, 11916.

[52] J. Klein, "Attention, scholastic achievement and timing of lessons," Scandinavian Journal of Educational Research, vol. 45, no. 3, pp. 301-309, 2001.

[53] T. L. Ammons et al., "The effects of time of day on student attention and achievement." 1995.

[54] R. J. Callan, "Giving students the (right) time of day." Educational Leadership, vol. 55, no. 4, pp. 84-87, 1998.

[55] A. Lima, G. C. G. Varela, H. Silveira, R. D. G. Parente, and J. F. Araujo, "Evening chronotypes experience poor sleep quality when taking classes with early starting times," Sleep Sci, vol. 3, no. 1, pp. 45-8, 2010.

[56] M. T. Trockel, M. D. Barnes, and D. L. Egget, "Healthrelated variables and academic performance among first-year college students: implications for sleep and other behaviors," Journal of American college health, vol. 49, no. 3, pp. 125131, 2000.

[57] T. Roenneberg, A. Wirz-Justice, and M. Merrow, "Life between clocks: daily temporal patterns of human chronotypes," Journal of biological rhythms, vol. 18, no. 1, pp. 80-90, 2003.

[58] C. S. Smith, C. Reilly, and K. Midkiff, "Evaluation of three circadian rhythm questionnaires with suggestions for an improved measure of morningness." Journal of Applied psychology, vol. 74, no. 5, p. 728, 1989.

[59] J. A. Horne and O. Ostberg, "A self-assessment questionnaire to determine morningness-eveningness in human circadian rhythms." International journal of chronobiology, vol. 4, no. 2, pp. 97-110, 1975.

[60] B. Griefahn, C. Künemund, P. Bröde, and P. Mehnert, "Zur validität der deutschen übersetzung des morningnesseveningness-questionnaires von horne und östberg," Somnologie, vol. 5, no. 2, pp. 71-80, 2001.

[61] I. Ajzen, "The theory of planned behavior," Organizational behavior and human decision processes, vol. 50, no. 2, pp. 179-211, 1991.

[62] H. Aarts, B. Verplanken, and A. Knippenberg, "Predicting behavior from actions in the past: Repeated decision making or a matter of habit?" Journal of Applied Social Psychology, vol. 28, no. 15, pp. 1355-1374, 1998.

[63] R. West, "The multiple facets of cigarette addiction and what they mean for encouraging and helping smokers to stop," COPD: Journal of Chronic Obstructive Pulmonary Disease, vol. 6, no. 4, pp. 277-283, 2009.

[64] B. J. Fogg, "Persuasive technologies," Communications of the $A C M$, vol. 42, no. 5, pp. 26-29, 1999.

[65] - "Persuasive technology: using computers to change what we think and do," Ubiquity, vol. 2002, no. December, p. 5, 2002.

[66] D. Lockton, D. Harrison, and N. A. Stanton, "The design with intent method: A design tool for influencing user behaviour," Applied ergonomics, vol. 41, no. 3, pp. 382-392, 2010.

[67] J. Redström, "Persuasive design: Fringes and foundations," in Persuasive Technology. Springer, 2006, pp. $112-122$.

[68] B. J. Fogg, "Creating persuasive technologies: an eightstep design process." in Persuasive, 2009, p. 44.

[69] A. R. Hevner, S. T. March, J. Park, and S. Ram, "Design science in information systems research," MIS quarterly, vol. 28 , no. 1 , pp. $75-105,2004$.

[70] S. Gregor and A. R. Hevner, "Positioning and presenting design science research for maximum impact," MIS quarterly, vol. 37, no. 2, pp. 337-356, 2013.

[71] J. F. Nunamaker, Jr., M. Chen, and T. D. M. Purdin, "Systems development in information systems research," in System Sciences, 1990., Proceedings of the Twenty-Third Annual Hawaii International Conference on, vol. 3. IEEE, 1990, pp. 631-640.

[72] K. Peffers, T. Tuunanen, M. A. Rothenberger, and S. Chatterjee, "A design science research methodology for information systems research," Journal of management information systems, vol. 24, no. 3, pp. 45-77, 2007.

[73] H. Pashler, D. Rohrer, N. J. Cepeda, and S. K. Carpenter, "Enhancing learning and retarding forgetting: Choices and consequences," Psychonomic bulletin \& review, vol. 14, no. 2, pp. 187-193, 2007 